\title{
THE INFLUENCE OF TECHNOLOGICAL DEVELOPMENT ON THE SUSTAINABILITY OF ARCHITECTURAL HERITAGE (DOCUMENTATION AND PRESERVATION) - CASE STUDY: CITADEL OF QAITBAY
}

Loka EL-DARIER, Lubna EL-DARIER, Suzan HASSAN, Dalia AL-ABASSY *

Faculty of Fine Arts, Alexandria University, Egypt

\begin{abstract}
The research aims to study, document and record heritage buildings. It is considered a step to preserve the heritage environments for their durability by introducing a 3D interactive models that include all data and details of the building. This can be achieved by using computer software to produce the virtual heritage to present the architectural heritage with the lowest possible costs, in addition to the following goals: Documentation the historical building as an initial step in the process of preserving the building and its durability. Moreover, Developing the search base and the historical analysis of the building. The research studies the modern methods of architectural documentation of the historical sites in Alexandria; (Citadel of Qaitbay) as a case study, which uses modern, simple and low-cost techniques. The documentation process exceeds preservation to provide all the building 's online information to serve researchers, architects and visitors.
\end{abstract}

Keywords

Heritage Buildings, Computer Software, Architectural Documentation, Preservation, Historical Sites, Forgery.

\section{Aim of the Research:}

The research aims to study, document and record heritage buildings. It is considered a step to preserve the heritage environments for their durability byintroducing a 3D interactive models, that include all data and details of the building. This can be achieved by using computer software to produce the virtual heritage to present the architectural heritage with the lowest possible costs, in addition to the following goals:

- Documentation the historical building as an initial step in the process of preserving the building and its durability. ${ }^{1}$

- Developing the search base and the historical analysis of the building.

- The research studies the modern methods of architectural documentation of the historical sites in Alexandria; (Citadel of Qaitbay) as a case study, which uses modern, simple and low-cost techniques. The documentation process exceeds preservation to provide all the building's online information to serve researchers, architects and visitors.

\footnotetext{
${ }^{1}$ UNESCO- ICCROM (2003). "Introducing young people to heritage site management and protection", first published, UNESCO Amman office, Jordan.
}

*Corresponding author: finea-dean@alexu.edu.eg 


\section{Research Importance:}

- The surrounding political circumstances requires us to preserve theEgyptian heritage that we inherited from different periods of history.

- The architectural documentation of the historical sites in Alexandria willpreserve them from oblivion, waste and Forgery.

- The modern technology of architectural documentation of historical sites inAlexandria are important methods of maintenance and restoration of thesesites, preserving them and their features and reviving them again.

\section{Research Problem:}

- The lack of resources and references in this field.

- Few institutions that interested in preservation and architectural documentation in the historical sites.

- The lack of modern documentation methods, experiences and competencies in the documentation field.

\section{General Concepts:}

\section{- Historical Location:}

The historical site is any site lived more than 100 years or more as long as it has a historical value. This value is presented in the importance of the event related to the construction of this location. The historical site provides a senseof magnificence that makes us want to know the culture that created it as it appears in the artistic, historical, political values in addition to the symbolic values.

\section{- Architectural Documentation:}

Architectural documentation is one of the scientific research processes as it isa documentation process of facts and information by describing or drawing an element of the composing elements of the architectural location.

\section{- Virtual Heritage:}

It is a term used to describe works that are manipulated by the information technology and communication i.e. the virtual heritage is a simulation of the characteristics of the historical site through a technological field. The manipulation of this technique was presented in the first time in an exhibitionin the British museum that was held in a conference in November 1994 in Britain.

\section{- Architectural Heritage:}

It is a range of facilities that proved its values and originality in the face of thechange forces. 
Thus, it became a visual reference upon the handling of man with the environment. The architectural heritage becomes a simulation of the characteristics of the historical site from an aesthetic side and a historicalvalue.

\section{- Architectural Identity:}

The architectural identity expresses a living and true expression of the culture of societies. It is the true translation of the character of the society in its physical and spiritual dimensions. It is a permanent reminder and a link between the great stages of development in the culture of the national personality. It is not synonymous with heritage architecture. Heritage is an influential factor. Architecture translates the cultural identity of the communityin the context of its human and cultural interaction through different times.

What is included in the architectural identity is an expression of awareness of the cultural identity and the understanding of the community and it's belongingto its national identity.

\section{- Architectural Style:}

Architectural style is a set of visual features that can be replicated in the sameorder and structure as a module, i.e., determining the style and method in the formulation of mass and architectural space in both aesthetics and functional terms. The architectural styles are classified in terms of form, techniques, materials, time, area, etc., which appear from the study of the history of architecture and consist of a number of features characteristic of each block and space surrounding it, the characteristics that gain the character of the mass and its surroundings and which distinguish it from others.

\section{- Interaction:}

Interaction means the responsive thing. It could be measured as a communication process when each message related to its previous one alternately. In this study, it means that the regular user gives order to explorea part of the virtual heritage for the system to display automatically it.

\section{- Documentation Process:}

the documentation process is from the oldest scientific research approaches.It is closer to apply the scientific theory upon the previous events, explain it, and try to interpret the present in the light of the previous events and developments.

\section{Introduction:}

The end of the last century, the world witnessed a great technological progress that is being used in operating all aspects of life through their enormous advantages comparing to the traditional methods. It is necessary tokeep up with this progress and use to achieve the maximum amount of interest. Especially, in the field of techniques an advanced modern 
equipmentappears every day in speed exceeds all expectations. In addition to the development of the operating systems and the applied system that perform in its environment and go along with this equipment.

This equipment provides users with tools and methods by which deal smoothly and easily with an amount of information that increasing spectacularly. It is necessary to mention that the phenomenon of the duplication of the intellectual storage during shortperiods resulted in the search and examination process of thee useful information has been become in impossible mission using the previous traditional ways manually or by out of date system. ${ }^{2}$

The constancy of the historical environment with its architectural and urban contents is a target sought by the countries as the studies that aim to keep thehistorical environment vary. There is no doubt that the studies of documentation and recording the historical data contributes in defining the heritage degree in terms of time and place, defining the heritage problems and the necessities of its preserving. These terms vary based on the life of theheritage, its conditions, its positivist circumstances and the surroundings.

Based on these terms, the suitable type of preserving between the reinvestment and using or just restoration and protection can be selected. Most of the times the ages of the architectural and cultural historical buildingsextend to ages exceed the age of the designers and dwellers of these buildings. When working on the preserving process It is necessary to providethe all the information and the building's details in terms of the horizontal projections, sections, the constructional status and other data. The sketching, documentation and recording these buildings are considered necessary and important steps before starting any processes whether restoration or preserving.

It is assumed at the state level that there are documentation andpreservation of all the architectural, urban and historical items. As well, therea classification and historical leveling that include level one, two, three, four and other levels. The documentation is done by drawings and the detailed description with pictures according to the architectural, urban and historical values of these buildings. ${ }^{3}$

From the theoretical side, the research shows how the computer techniques contribute as a tool in documentation and bringing the historical and architectural items of the historical buildings. Also, how to use the $3 \mathrm{D}$ documentation to reach the constancy of the historical environment

\footnotetext{
${ }^{2}$ Alian, Beauty (2005). "To maintain the heritage Althagava- toward Arab school to preserve the cultural heritage and its management" - a series of books the world of knowledge, politics Press, Kuwait.

${ }^{3}$ Baz, Munir (2006), "Dealing with the elements of the internal architecture of the re-employment of valuebuilding projects" - Master, Faculty of Engineering, Cairo University, Cairo, Arab Republic of Egypt.
} 
and recode the historical status from the architectural and constructional aspect asit includes the historical background, demonstration of the idea and the designconsiderations. The applied part deals with the initial steps to document the Citadel of Qaitbay. It is supposed to extend to include advanced phases to overall documentation of the data of the architectural and urban heritage of Alexandria.

\section{Documentation and the Durability of the Urban Historical Environments:}

The importance of the urban heritage emerges in many aspects; the most important of them are the cultural aspect, the scientific aspect, the touristic aspect. The cultural aspect emerges in the fact that the traditional buildings are an interpretation of the history and values of societies, which necessitatesthe need to communicate with him. The scientific aspect of the urban heritagecould be noticed through stability and measurement as one of the scientific methods in the field of the urban science.

The historical models are considered the most important sources of knowledge and measurement. No nation seeking civilizational constancy depends totally on exotic models and neglect its original ones. The urban heritage includes basics and principles that must be notices, understand and imitate it to help in develop our contemporary urban data on the level of the cities, urban planning, and theurban vocabulary as mosque, houses, streets, markets, etc. the urban heritage is a tourist attraction but not as a portrait from the past.

It is for its ability to understand some activities that the modern cities lost it and many long for it. Therefore, the ancient places became a complement part of the knowledge, entertainment and picnicking in the modern cities. The studies that handle How to sustain heritage environments include the following axis:

- First: the discussion of the current situation of the heritage environmentby counting the sites of the urban heritage and classify them then evaluate the current situation of the urban heritage and the cultural, social and economic importance of the urban heritage environments.

- Second: the protection of the urban heritage, developing it and reusing it. Discussing the organizational polices that are proper for handling theurban heritage and the systems of counting the heritage sites, classify them, investing the urban heritage and restoring it.

- Third: the role of different parties in developing the urban heritage,developing, managing and defining the role of the individuals, the society and organizations in preserving the heritage.

- Forth: the touristic development of the urban heritage by providingalternative opportunities 
for the economic and social benefits to develop and reinvest the urban heritage.

- Fifth: the distinctive experiments of the countries, institutions and organizations in registration, reinvestment and touristic usage of theurban heritage, the development methods and keeping it.

\section{The Architectural Documentation is the First Step of the Constancy of the Heritage Data}

\section{That Leads to:}

- The increased awareness of the importance of the urban heritage as acultural and economic source

- Identifying the means of protecting the heritage and reusing it within acontemporary context.

- Finding the basics and planning and design standards to develop theheritage data.

- Identifying the environmental and cultural aspects affecting the structureand the character of the local architecture.

- Presenting the economic value in the urban heritage and its importancein the economic development

- The exchange of experiences and experiments in the field of preserving,documenting and classifying the site of the urban heritage, keeping it and its rehabilitation

\section{The methodology of the study to document the historical sites topreserve them:}

An integrated methodology is set for the study. It is presented in two basic stages since every stage has its sequenced steps up to the final project (See Figure 1)

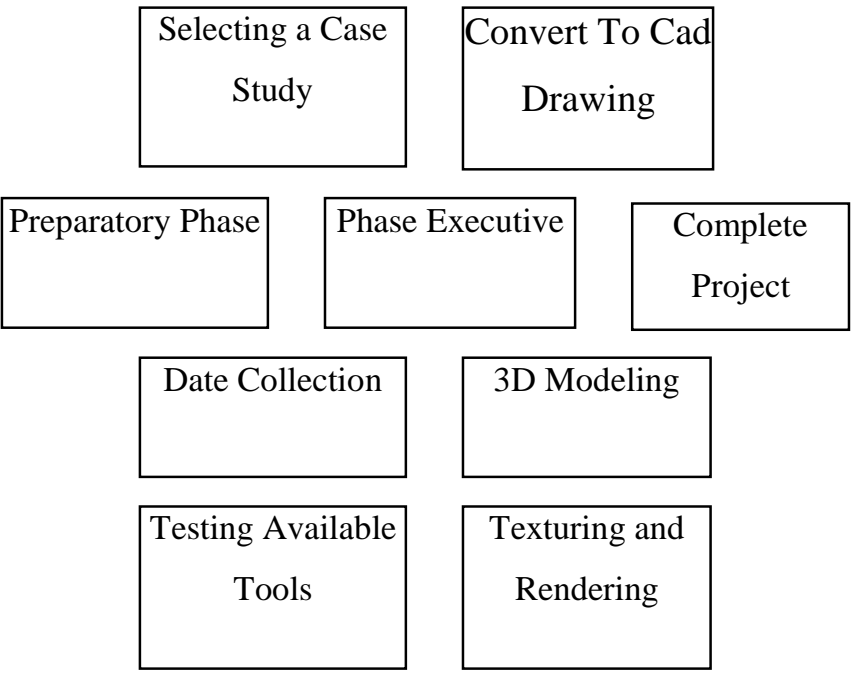

Fig. (1) Diagram explain the methodology of the study to document the historical sites. 


\section{First: The Preparation Phase:}

It includes several sequenced stepsrepresented as follows:

\section{1) The Phase of Choosing the Case Study:}

The case study is chosen for itsdiscrimination and historical and architectural value in terms of the distinctive aesthetic elements and related to the period of its construction and durability through preserving and registration.

\section{2) Collecting Data Phase:}

This phase is considered from of the most important preparation phases. It is a compilation of all the data relatedto the origin regardless of the occurring changes throughout history.

\section{A: The Study of the Historical Data:}

It presented in the study ofthe descriptions of the travelers, men of history, verbal information and the historical phases that passed by it and itsinfluence on the facility until now. ${ }^{4}$

\section{B: The Study of the Construction of the Building Internally and Externally:}

It presented in preparing all plans and the horizontalprojection, elevations, sections and details whether old or new.In addition to doing the sketching, photography, and analyzing these images.

\section{C: The Study of the Surrounding:}

It is a detailed study of theoriginal and local structure of the surroundings.

\section{3) The Phase of Defining the Aiding Tools:}

In this phase, all aiding tools are chosen based on their availability and flexibility. The aiding tools means the software and the means of communication and simulation as there is harmony between the different techniques. The user interface fulfills all the needs to explore different parts of the project.

\section{Second: The Implementation Phase:}

This phase includes several stepsthrough use several software in the data that have been obtained in the preparatory phase. It enables getting information in interactive way to reach the final Project. Based on the related data of the historical building, the project must containthe following characteristics:

1) The three-dimensional object is susceptible to examination of all ofits parts and details. It is preferred to link some details with its historical contents.

\footnotetext{
${ }^{4}$ Balawi, Mahmoud (2010), "a lecture entitled maintaining Urbanism" - Department of Architecture Faculty of Engineering, Islamic University Bgzh- Palestine.
} 
2) The user should be able to observe and discover of the $3 \mathrm{D}$ object ina real time through an interface that is easy and flexible. It is controlled by the mouse.

3) The availability of panoramic observing in 360 degree of the 3Dobject or the internal spaces.

\section{The Method Used in the Architectural Documentation of the Historical Sites:}

The architectural documentation process of many and various historical sitesvaried in the importance based on the historical site and its historical values. All methods depend on recording, classification and documentation by photography and geometric sketching. The followed methods divide into two means:

A. The traditional way that depends on the manual effort and the individual abilities. It is performed by manual means and the traditionalmeasurement tools that contains mistakes and costly in time and effort. ${ }^{5}$

B. The second mean: is the modern way which is called the electronicdocumentation and it is our research subject ${ }^{6}$

\section{The Modern Methods in the Architectural Documentation Electronic Registration:}

Through the great technological development that the world witnessed today,many different international organizations, governmental or private, use this great development in the architectural documentation in electronic means depending on the recent and advanced means. Documentation of architectural significant buildings is essential and vital forpreservation and conservation purposes. Such documentation must be systematic, accurate and true in representing distinctive qualities; and mustfollow an appropriate procedures.

\section{The Tools and the Recent Means Used in the Architectural Documentation:}

The tools and the modern means used in the architectural documentation process that is provided by the modern technology today in all aspects of life especially in the documentation process to transfer the all data, information and the paper photos to the electronic form by using scanners. From themodern tools and means:

\section{First: Documentation by Photometric Camera:}

A digital camera is used to capture photos and record videos of the historicalsites and buildings effectively and clearly. They are transferred very quickly and easily everywhere in the world. They are used directly in defining and processing the historical sites or enrolling them in the database. They could be stored using the modern techniques as DVD. This device has a great

\footnotetext{
${ }^{5}$ Shull,c., 1999 "Photogrammetry and the Archeology of Buildings", unpublished M.Sc. thesis, University of Cape Town, South Afric

${ }^{6}$ Boujemaa, behind God and others (2009) "The role of electronic documentation in the maintenance of urban and architectural heritage in Palestine" - University of M'sila, Algeria.
} 
importance because of its accuracy in documentation and the easiness and quickness in implementation that combines between the photographic and metric documentation at the same time.
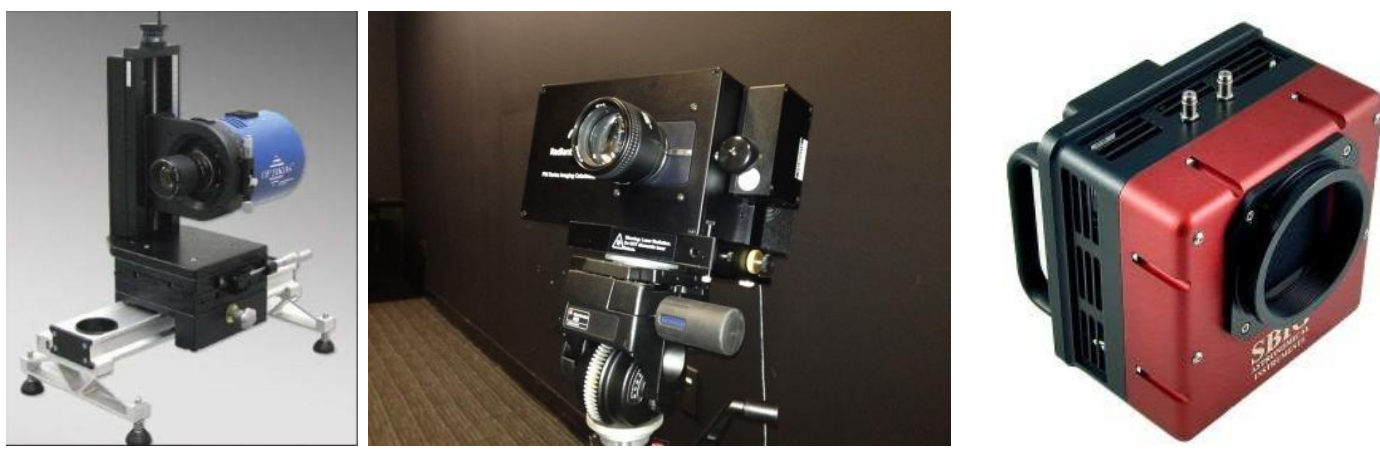

Fig. (2) Photometric Camera Device.

\section{Second: Documentation Using Total Station Device:}

It depends on knowing the coordinates of certain points inside and outside thebuilding. The coordinates of these points connect with each other. Then the Total station device is connected to the computer. Certain software connects between these points for getting the horizontal projections and elevations of the buildings.

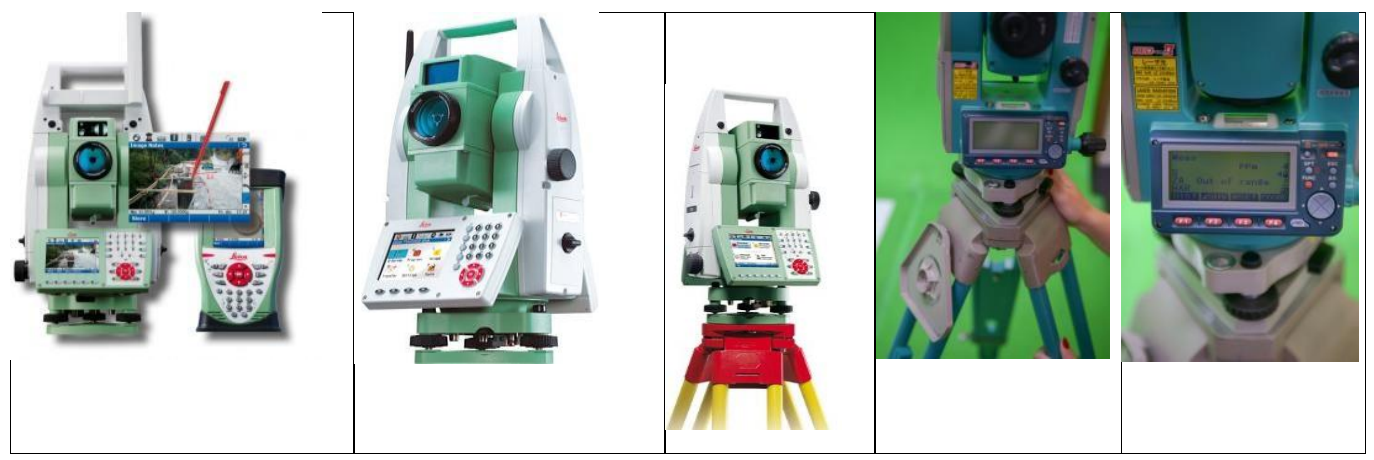

Fig. (3) Total Station Device.

\section{Third: Documentation Using Photogrammetry:}

Developments in the sciences of photogrammetry and image processing overthe past decade or so have seen an increase in the automation of the data collection process, ranging from high precision industrial applications throughto simple solutions for non-traditional users (for example, 3D Builder and Photo Modeler). In addition, systems that use imagery from consumer digital and analogue video systems and sequences of images have almost automated the creation of three-dimensional (3D) models (as has the development of 3D laser scanners.

The Photogrammetry is a science, art and technology of getting quantity andquality information (coordinates, dimensions, shapes,...) related to buildingsor objects on the ground whether on 
paper od electronic (digital) of direct photos without the effort of the fieldwork in measuring and registration.

The photography, ground or air, brings the photos to very sophisticated devices but easy to use (analytical or digital plotters). They process in a scientific specific ways. The documentation in the form of numbers or electronic or paper maps based on the used techniques. There are types of the Aerial surveys devices as the manual, analytic and digital. The digital one is more common because of the development of the computer techniques andthe cadastral industry development in many countries. The techniques of the Photogrammetry uses the same technique of the aerial photography with some difference in the process of controlling the photos and prominent differences in the geometric applications naturally. ${ }^{7}$
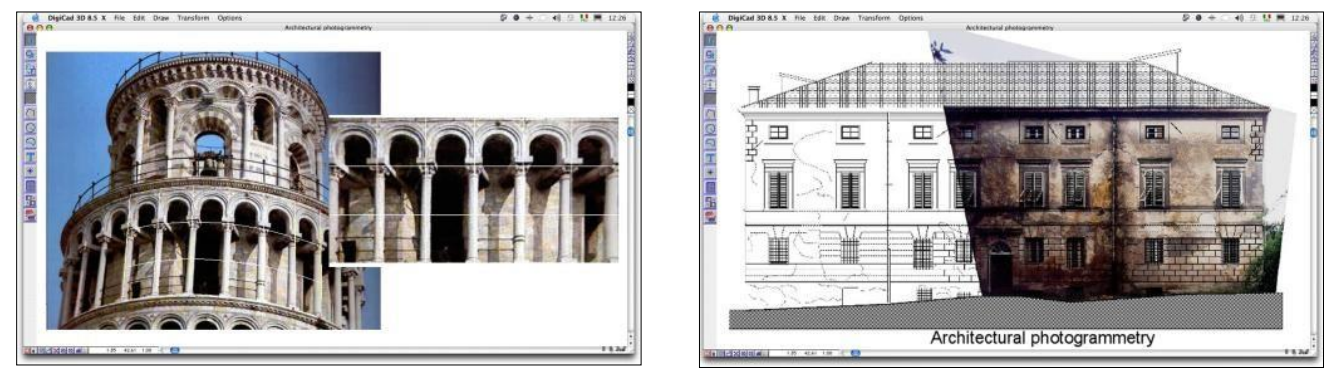

Fig. (4) The DigiCad 3D Imaging System That Requires High Sensitivity Digital Cameras.

\section{Fourth: Documentation Using 3D Laser Scanning:}

This is the most accurate technique in addition to its ability to document decorations and places that are hard to reach. This technique depends on adevice that forms a data cloud. This cloud consists of small particles when they hit the buildings parts they record the coordinates XYZ. By using certain computer software, the coordinates are read and a full drawing of the building from inside and outside is performed.
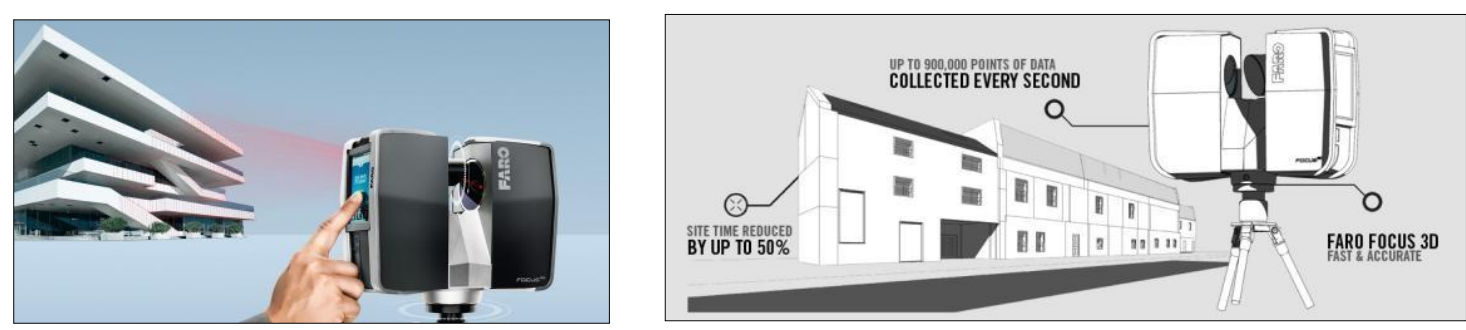

Fig. (5) The 3D Laser-Scanning Device.

\footnotetext{
${ }^{7}$ Mohammad, Amal Abdul Waris et al. (2005) "architectural documentation of historic buildings in the light of the digital revolution" - the Sixth International Scientific Conference and its impact on architecture and urbanism, Faculty of Engineering, University of Assiut, Egypt.
} 


\section{Fifth: Documentation Using the Technique of the GeographicInformation System:}

This modern technique spread in the late eighties and early nineties. It depends on the computer software that could mix between information from various sources to produce more accurate and comprehensive information from the individual sources.by these software mix the ground data collected by Total station, GPS data, data from aerial photo and data from spatial photo. These data bends together, enrich the knowledge of the user, and helphim after its processing to understand well the studied aspects. Thus, reaching the suitable decision. It is an effective method for the decision makers and learners. Often, an integration between various techniques happens to serve the desired goal.

The specialist in preserving the historical environment use documentation andrecording widely in some environmental issues as the pollution of the air, water and soil. It gives the technique of photography with its various kinds a more comprehensive view of the place of study. He obtains a Statistical data that helps him in closer studies on a small scale. The role of the documentation and recording is not limited to monitoring but the contribution in understanding the type of pollution, evaluate its influence on the historical environment, and try to suggest the suitable ways to avoid it or reduce it.

In addition, who search in monuments could use documentation and recording techniques in searching for it by examining its characteristics in the aerial andspatial photos. It increase the benefit of the application of documentation and recording in the archeology. The fast progress in the methods of automaticexplaining and analyzing of photos is beneficial in the ability to process thehuge multiple source data in using and transferring these data online that spread widely every year. ${ }^{8}$
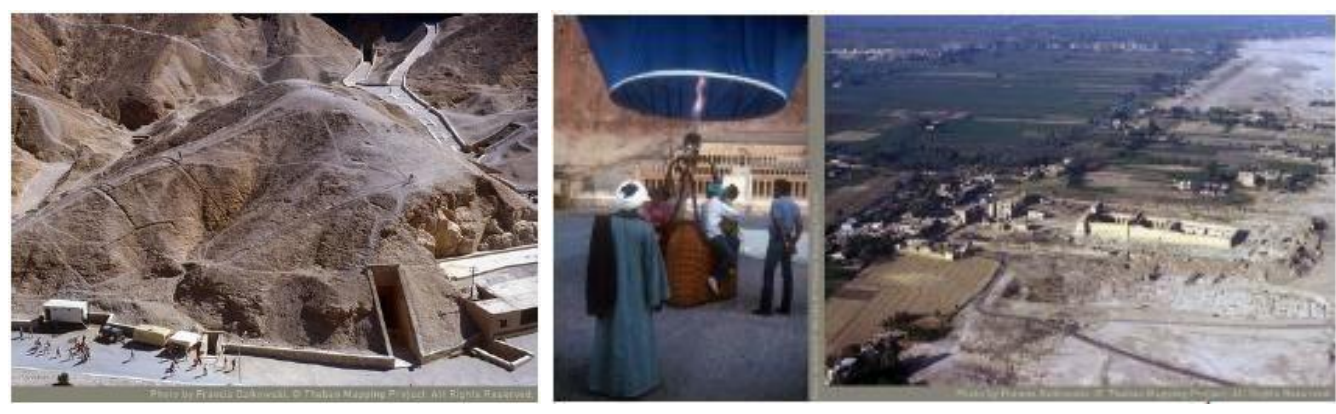

Fig. (6) Thebes Atlas of Al Barr Al Gharby and using the technique of the aerial photography,remote sensor, geographic data, Photography and data display online.

\footnotetext{
${ }^{8}$ Muheisen, Ahmed et al. (2008), "Study of Center for Architectural Heritage in documenting archaeological and historical sites in Gaza City" - the First International Conference on Architectural Conservation, Center for Architectural Heritage, the Islamic University Bgzh- Palestine .
} 
Atlas and the map of Thebes in Al Barr Al Gharby" is considered an example of using various techniques in documentation and recording as it shows everycemetery documented with a number that recall the related data. The dealingwith it is done by computer software and the internet. In addition, you can get all the information from architectural drawings of the horizontal projections, section, coordinates, historical studies and other information.

\section{Texture Mapping and Visualization:}

A three-dimensional photo-model is an object model where the texture information is taken from photographs or other optically working recording systems. It consists of two parts. One part is the three-dimensional object model in which the shape of the object surface is stored. Adjoining surfacepatches approximates the object itself. The second part is the photo texture, which is transformed to the patches.

\section{GIS:}

GIS is an important tool for urban planning. GIS includes software and hardware tools, and a group of procedures elaborated to facilitate the capture,edition, administration, manipulation, analysis, modelling, representation and the exit of spatial referenced and semantic data, to solve any type of planning,administration, storage, and further information concerning the problem

The Different Types of the Architectural Documentation Related to the Archeological Sites:

\section{First: The Geometric Documentation:}

It depends on the documentation using the method of taking measurements on the shapes of triangles. It isnecessary to geometrically sketch the building on the plan and link all the geometric voids in a triangle net to assure accuracy in sketching.

\section{Second: The Documentation of the Construction Materials:}

It is a very important type in preserving the archeological element existing in the site.You can get the details that constituted the archeological element with thehelp of experts in the science of the construction materials to define the types of the existing construction materials in the archeological element (wood, rock, metal...) and others.

\section{Third: Documentation of the Decoration Graphics:}

It is an important partin the documentation. The most common method is tracing the graphic then draw it carefully and accurately on paper then scan it using the scanner to get a photo you 
can deal with on computer by the geometric software. ${ }^{9}$

Case Study: (Presentation of the Architectural Heritage of Citadel of Qaitbay in Alexandria (The Main Tower):

The aim of this study is scanning, documenting and recording the site on the computer with taking into account the high cost of the scanning and sketchingdevices. In the time of having an infinite number of buildings and environments that are required to document.so, this experiment shows how work within the reasonable possibilities achieve a high degree of competencein documentation and recording heritage

\section{Introduction about Alexandria:}

It is an ancient city where several civilizations and cultures developed on its land. It is characterized by an architectural heritage that is still influential until the present time. Alexandria is characterized by its strategic site among contents, its fertile land and its moderate climate. It is a coastal city where many castles and military and commercial ports were built on its shores.

Therefore, it was a battlefield for wars and conflicts.

Consequently, Alexandria faces threatening risks. The most important is the wrong interventions, carelessness and the massive increase in population. Hence, the historical building will not survive through few years if the specialists do not take any practical procedures to preserve these building byrestoring and reviving these landmarks.

\section{The Preparation Phase:}

\section{First: Criteria of the Case Study:}

The case study is chosen based on the following criteria:

- Its importance in terms of being one of the outcomes of the local heritage in addition to the historical and cultural value that consistthe historical structure in the region.

- The rareness of the chosen case study in terms of type andvanishing of the similar cases

- The easiness of access to the location, investigation and dataanalysis.

- The ability of making full architectural sketching study for the currentsituation

\section{Second: The Description of the Case Study (Citadel of Qaitbay):}

Pharos Island In the far west of Alexandria.it is constructed in the place of the ancient lighthouse of Alexandria that fell down in 702 A.H. because of the destructive earthquake that happened in the era of Sultan Nasser MohammedBin Qalawun. Sultan Al Ashraf Abu Al-Nasr

\footnotetext{
${ }^{9}$ Popular Architecture Center "gallery" (2011), "National Register of monumental buildings" - Ramallah, West Bank, Palestine.
} 
Qaitbay built this citadel in 882 A.G. and finished it in 844 A.G. his concern with Alexandria was because ofthe large number of direct threats to Egypt from the Ottoman Empire that threatened the whole Arabic region. Mamluk sultan Qansuh al-Ghawri caredfor the citadel that increased its importance and arms.

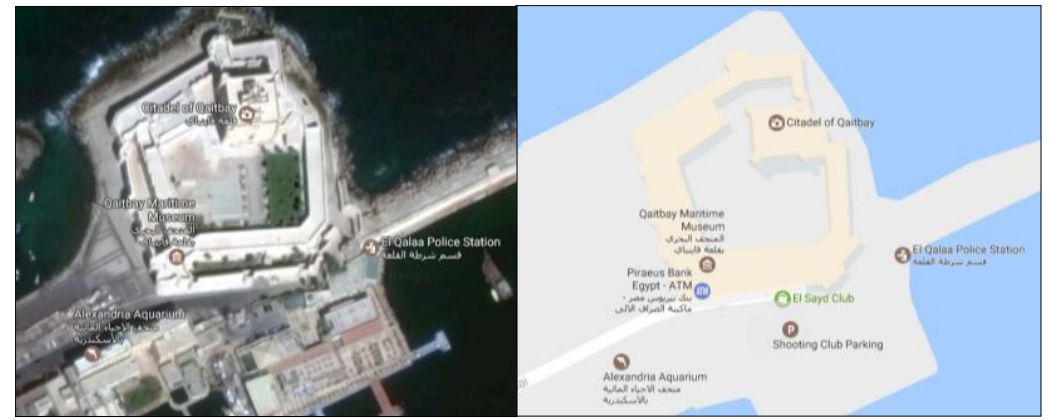

Fig. (7) Google earth Scenes that show the Citadel Site.

\section{The General Architecture Planning of the Citadel:}

The citadel is constructed on 17550 Square meters. On this area, the outer walls of the citadel and the military equipment were built. They are a group of walls were built to fortify the citadel. These walls consist of two great walls of huge rocks that surround the citadel from outside and inside to protect the citadel. The first wall is the outer one. It surrounds the citadel from the four direction. The eastern side overlooks the sea. It is two meters width and eightmeters height. There are no towers on it. The western side is a huge wall witha larger thickness than the other citadel's walls. It contains three rounded towers. This tower is the oldest of all other parts. The southern side overlooksthe eastern harbor and contains three rounded towers with a door in the middle of the wall. The northern side overlooks the sea directly. It divides into two parts. The lower part is a big ceiled corridor was built directly on rocks. It has many rooms. The upper part is a corridor with narrow openings overlooksthe sea. The inner walls were built from rocks and surround the main tower from all sides except the northern side. This wall contains adjacent rooms areprepared to be barracks for soldiers. They have no openings except doors openings and slots to be vents or openings to defend from them. The main tower located in the North West side. The main tower is a square shape building consisting of three floors. Every corner from the four corners containsa rounded tower higher than the roof of the main tower. It was built from solid limestone.

\section{The Main Tower:}

The main tower in the inner yard form a shape of big square citadel. The length of the side 30 meter and the height 17 mater. It consists of three floors. On the four corners of the tower, there 
are semicircular towers ends on the top with prominent balconies with openings to fire arrows on two levels. The first floor contains a mosque. It consist of a courtyard, four halls and defensivecorridors to allow the soldiers to pass easily during defensing the citadel. The mosque had a minaret but it collapsed recently.

The second floor contains corridors, halls and internal rooms. The third floor contains a big room (The seat of Sultan Qaitbai) he sat on it to see the ships on a day's journey from Alexandria. A cross section dome covers it. This flooralso contains an oven to make bread made of wheat. A mill to grind the grain for the resident soldiers in the citadel. Sultan Qansuh al-Ghawri renewed thecitadel and increased its protections. This citadel is neglected during the Ottoman occupation of Egypt.

\section{Third: The Architectural and Graphic Sketching of the Study Case:}

It was chosen the main tower of the castle.

\section{The Architectural Sketching:}

The old and recent schemes were collected to know the historicaldevelopment of the building

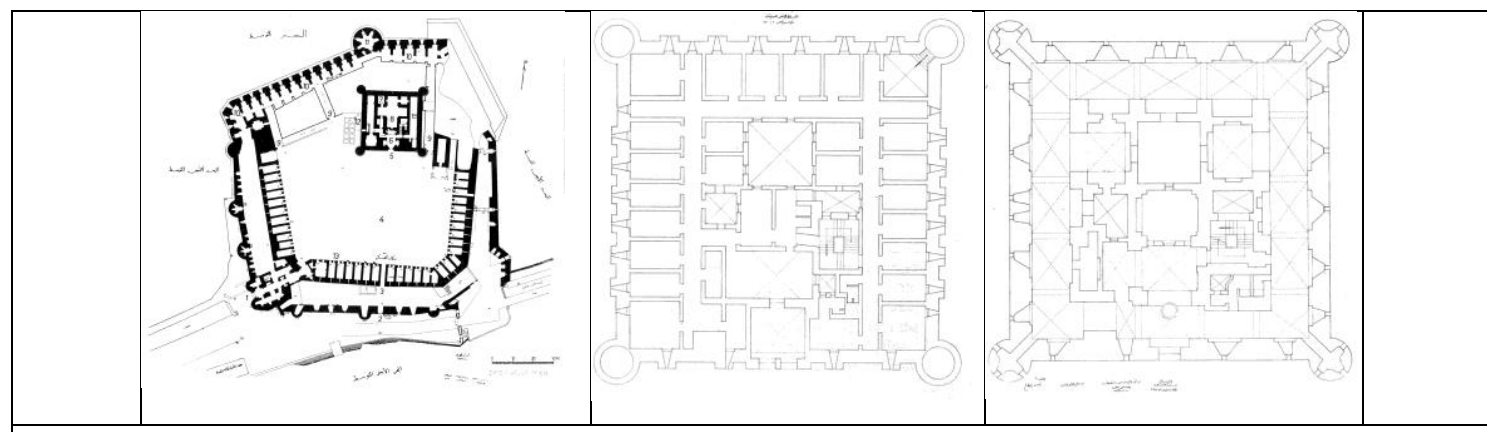

Fig. (8) On the left is a horizontal hometown showing the general layout of the castle and in the center and on the right the horizon of the first and second floor of the main tower of the castle.

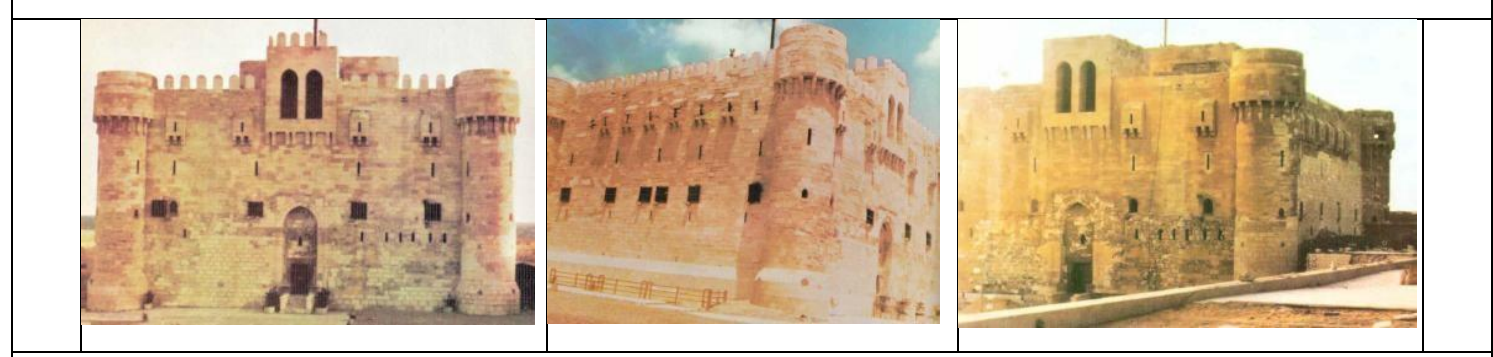

Fig. (9) Some of the facades of the tower of the castle after the restoration of the year 1949 of the book description of Egypt.

As for the current schemes. It was necessary to perform a fieldwork and manual sketching with the modern techniques to sketch all building's details as they did a manual sketching of elevations and the horizontal projection andall the details to include all parts of the building. Some measures were sketched manually, and other were concluded. 


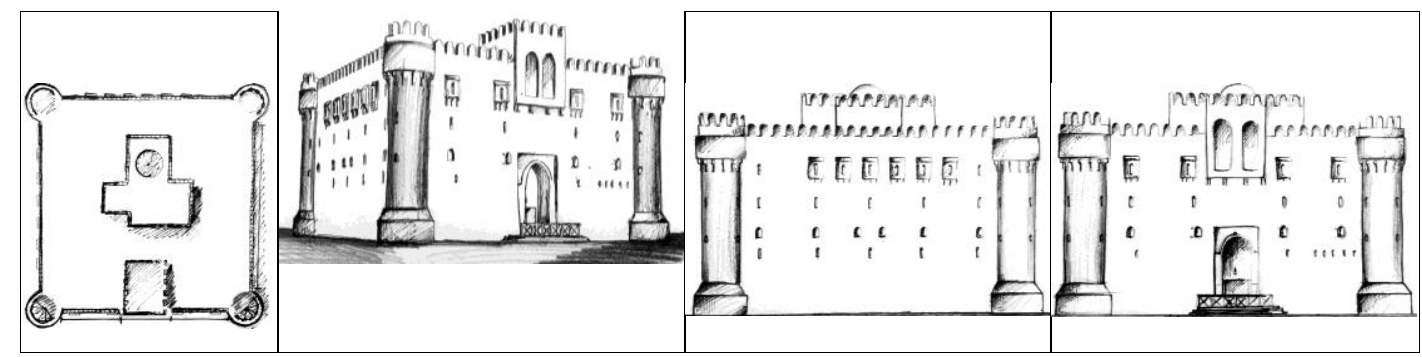

Fig. (10) Model of the hand drawings of the horizontal projection and the vertical projectionand the view of the main tower of the castle.

\section{The Graphic Sketching:}

The graphic sketching was highly accurate. It includes the details of the building. In addition, the picturing of the surroundings and pictures of thematerials used in the construction that the picturing is considered to not having a glare in the pictures and the transformation of the picture is minimum.

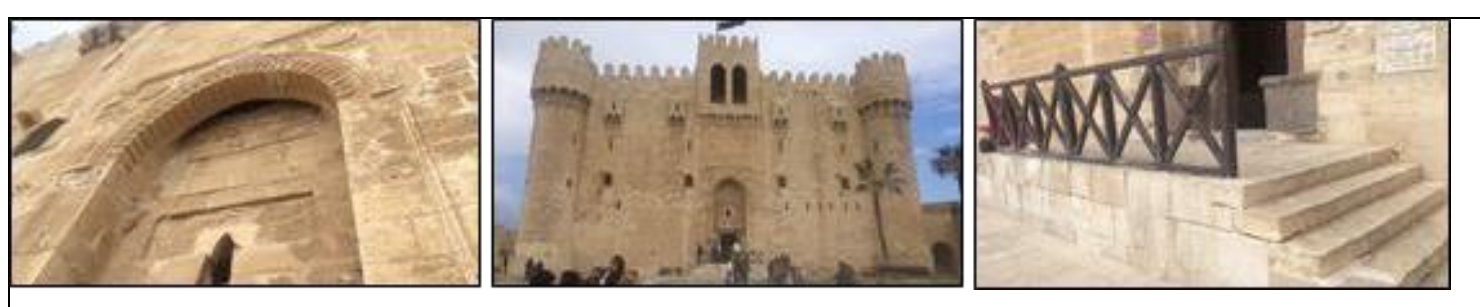

Fig. (11) The graphic elevation of the southern façade, showing the details of the entrancedoor and stairs.

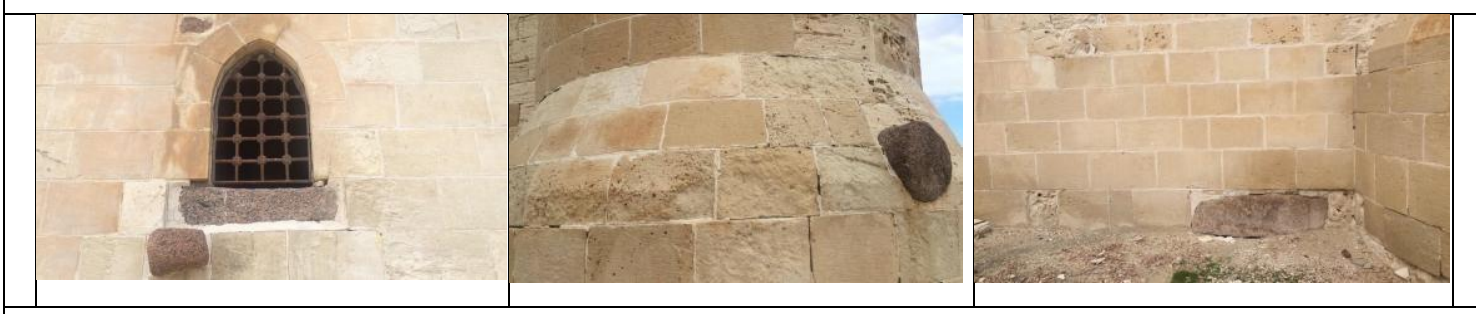

Fig. (12) The photographic elevation of some details of the main tower of the citadel.
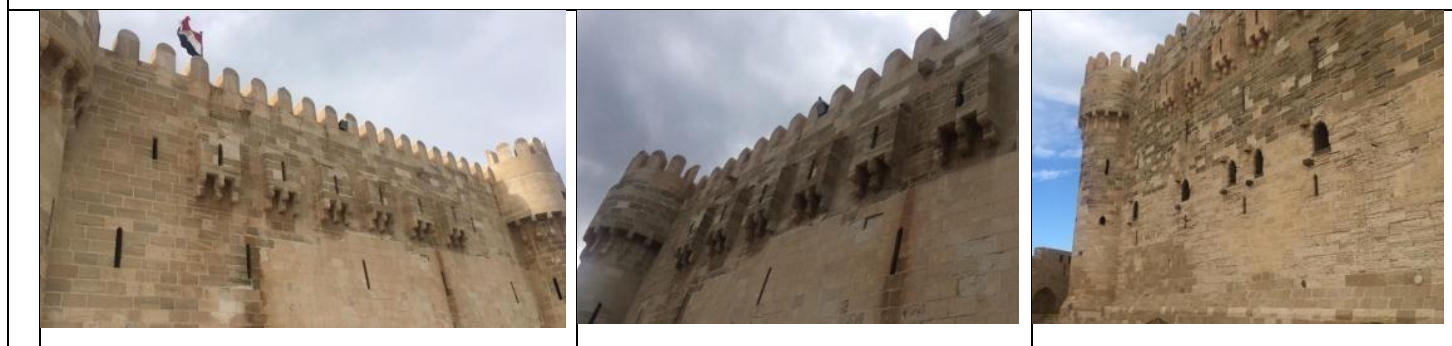

Fig. (13) The northern and western facade of the tower of the citadel. 


\section{The implementation phase using computer software topresent the study case:}

In this phase, the $2 \mathrm{D}$ schemes are transformed into $3 \mathrm{D}$. The pictures of the details and the materials are processed by choosing several software to meet the needs of the previous requirements and the work flows sequentially:
AutoCAD
Adobe Photoshop
Autodesk 3ds Max 2016
Cosmo Player

\section{First: The Implementation Phase Using AutoCAD:}

AutoCAD is a sketching and designing software. It support creating $2 \mathrm{D}$ and $3 \mathrm{D}$ drawings. In this phase, the manual drawings and sketches into 2D. In thecase of having $2 \mathrm{D}$ pictures of some parts of the building, (tracing) could be used using the Photogrammetric drawing.
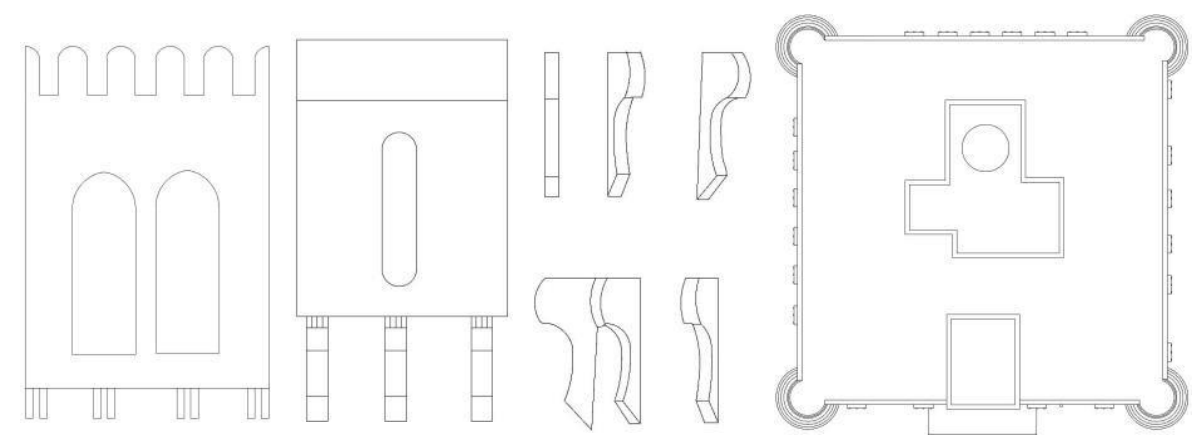

Fig. (14) Illustrates the conversion of hand drawings to 2D drawings, computerized and engineering, where the hollow of the tower of the tower of the castle and engineering drawings of some of the details.

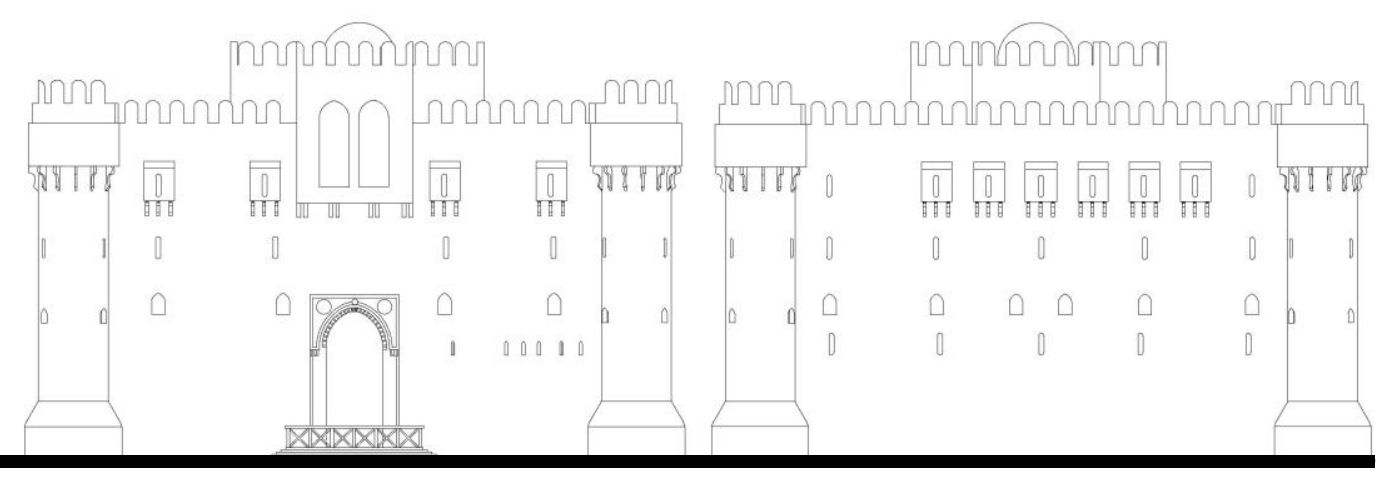

Fig. (15) Shows the conversion of hand drawings to computerized 2D graphics and geometry of the southern facade and the north facade of the tower of the tower using the program AutoCAD. 


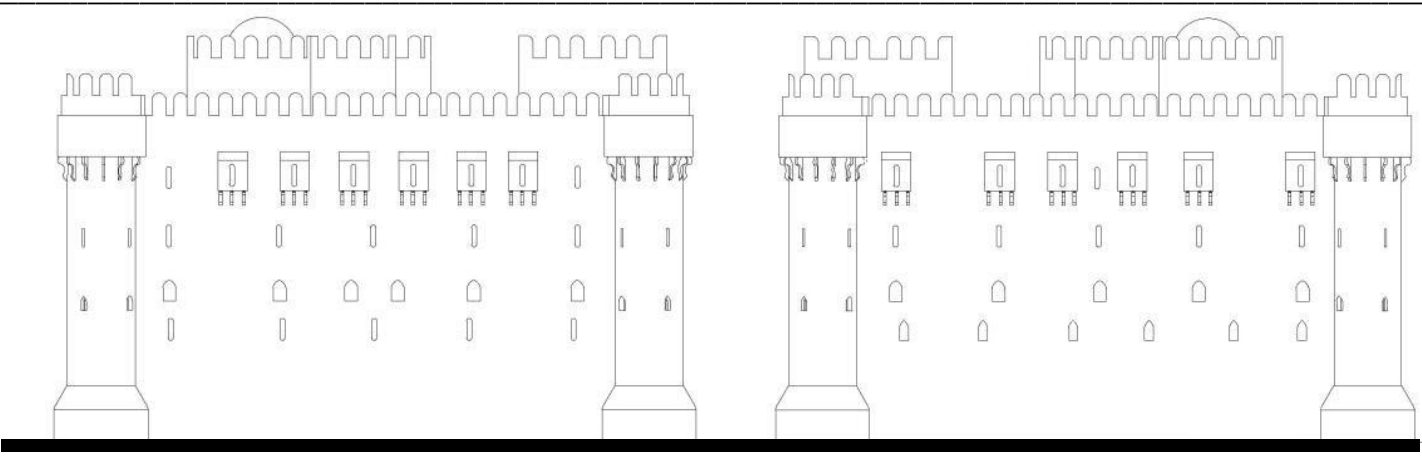

Fig. (16) Illustrates the conversion of hand drawings into two-dimensional computerized graphics and the geometry of the main tower of the castle using the AutoCAD program - on the right: the eastern façade on the left: the western façade.

\section{Second: The Implementation Phase Using Adobe Photoshop}

This software is used in image processing and preparing textures to be usedin the 3Ds Max. The software could serve in the transformation of the 2D pictures in case of unavailability of Photogrammetric. Thus, tracing could be done by AutoCAD.
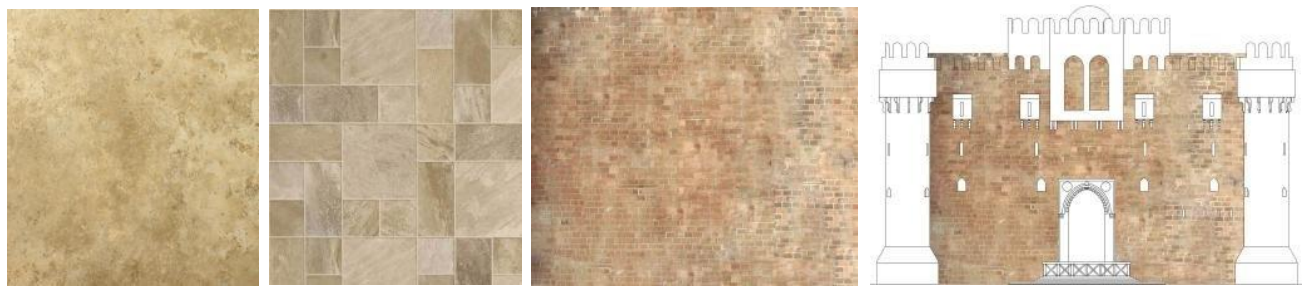

Fig. (17) Illustrates the processing of the fillings using Photoshop for the introduction of the 3D max program.
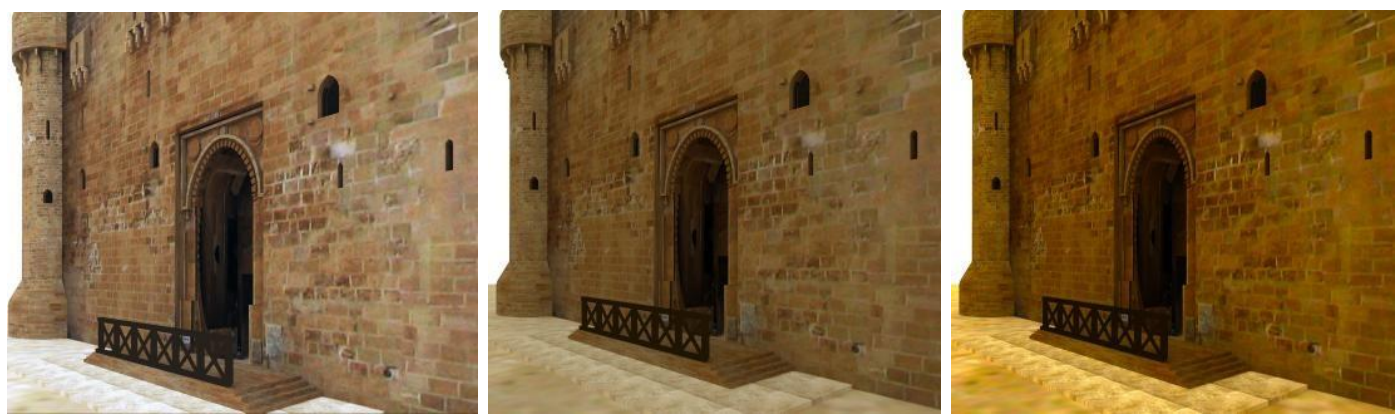

Fig. (18) Illustrates the processing of images through the Photoshop program.

\section{Third: The Implementation Phase Using 3D Max:}

In this phase, the drawings and 2D plans are transformed into 3D using 3DsMAX software or importing it from AutoCAD as it is very compatible with it. The software is used in texturing, lighting and rendering. It also export to VRML technique. It also can link some parts of the 
building with Hyperlink tosupport the virtual tour with some texts and instructions. ${ }^{10}$

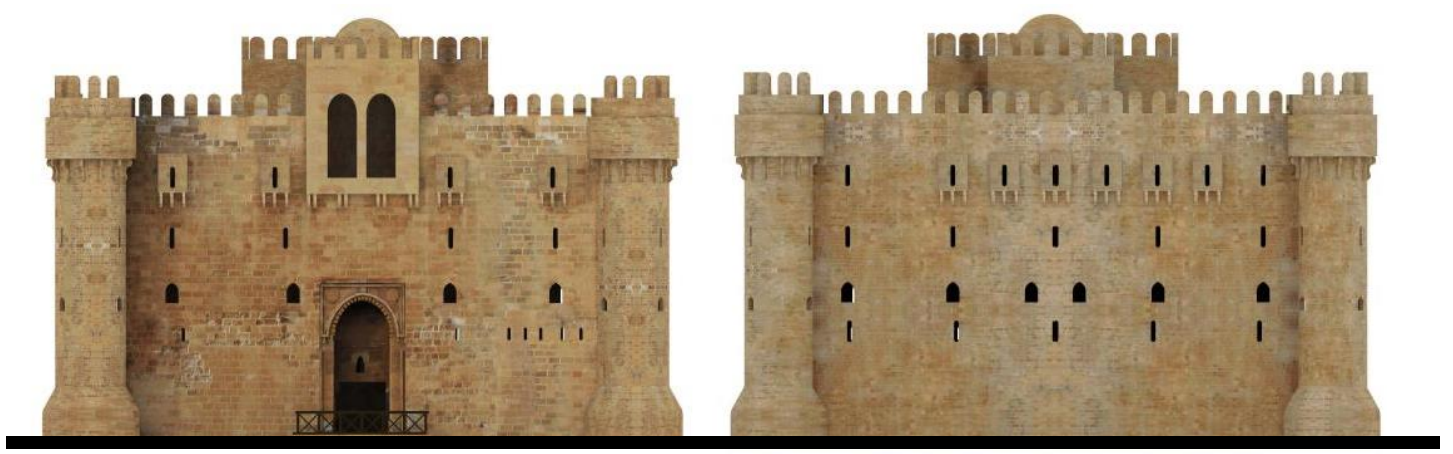

Fig. (19) 3D modeling using 3Ds MAX, which converts two-dimensional graphics into three-dimensional graphics and also enables Mapping \& Texturing, On the right is the northern façade of the main tower of the cauldron and on the leftthe southern façade.

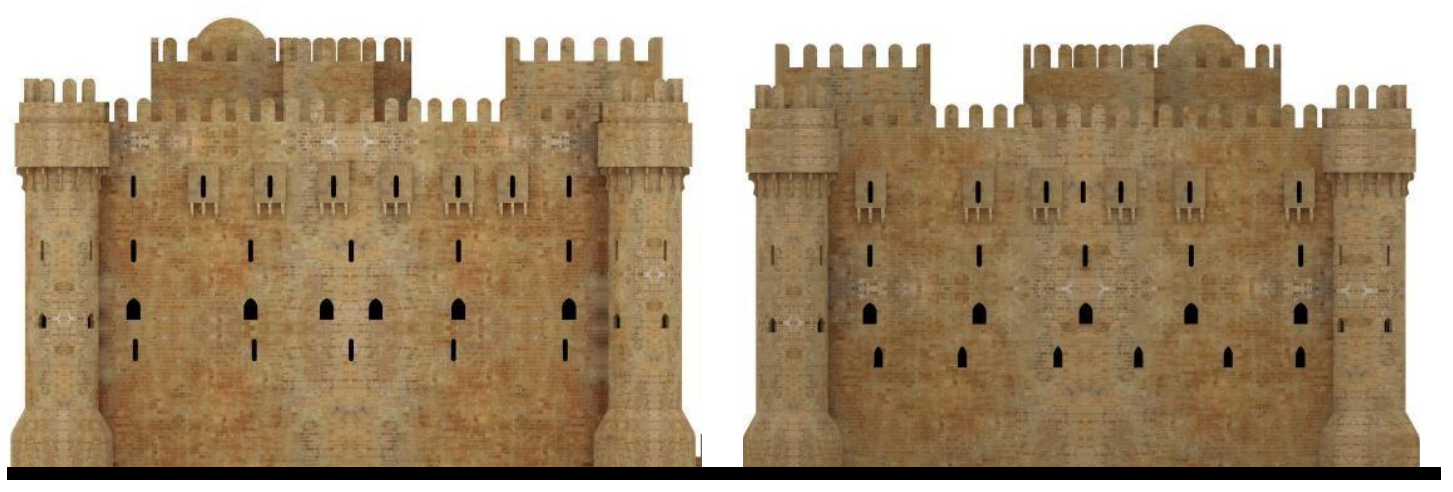

Fig. (20) 3D modeling using 3Ds MAX Program that allows Mapping \& Texturing, on the right is the eastern façade and on the left the western façade of the main tower of the citadel.
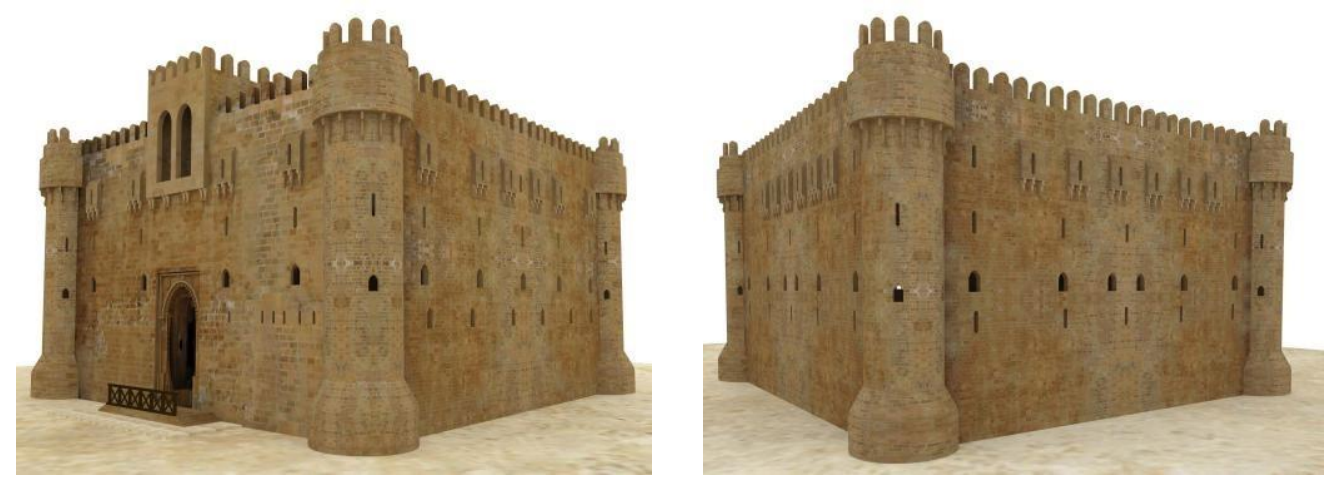

Fig. (21) Scenic snapshots of the main tower of the castle using 3Ds MAX Program.

\section{Fourth: The Implementation Phase Using 3D Printing:}

$3 \mathrm{D}$ printing is any of various processes in which material is joined or solidifiedunder computer control to create a three dimensional object, with material being added together (such as liquid

\footnotetext{
${ }^{10}$ Jaafar, Ashraf (2005), "use" modeling through images "in the three-dimensional positions of the heritage of Islamic architecture in Jerusalem embodiment" methods - paper, scientific research periodical Alengah- refereed issued by the Faculty of Engineering, University of Zagazig Branch Bhbra- Pinha- fourth Issue.
} 
molecules or powder grains being fusedtogether), typically layer by layer.
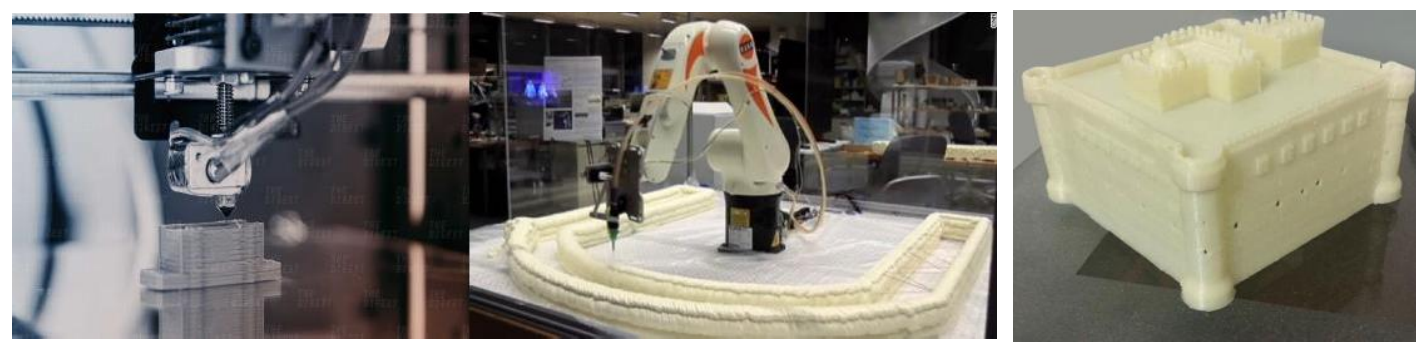

Fig. (22) 3D model of the castle using 3D printer

\section{D Documentation and BIM Modeling of Cultural Heritage:}

During the last years, the application of 3D technologies to Cultural Heritage has provided successful results, with impact on preservation, valorization andheritage transmission. Now, the emergences of 3D printers open new horizons for the heritage sector.
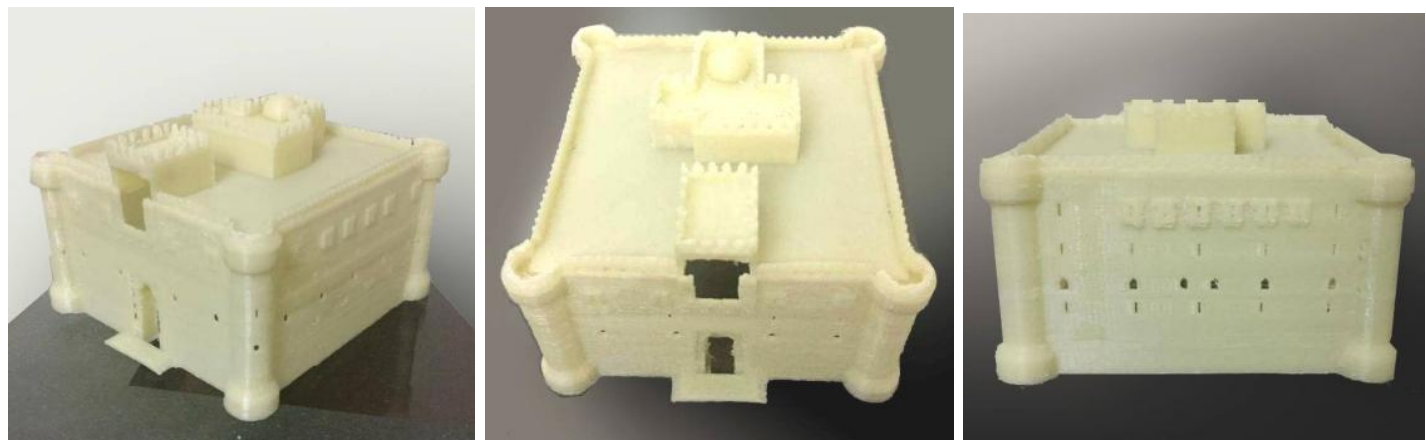

Fig. (23) Example of 3D model of a complex heritage site, visualization of the 3D point cloudof the overall building.

\section{Semantic Heritage-BIM:}

The integration of semantic attributes with hierarchically and mutually aggregated 3D geometric models is indispensable for management ofheritage information.

3D parametric and semantic modelling will lead to the development of semantic 3D reconstructions of heritage building and sites, integrated withadditional documents (i.e. pictures, maps, literature) and intangible information.

\section{Results:}

- This work is an initial step of more advanced phases. Completion of the workrequires institutional and financial support, possibilities, information and constant effort. The idea of 
the constancy of the heritage exceeds the preservation process to a complete system of heritage management. Heritageis no longer a record of the past but it became a part of the urban identity and a way to build the future.

- The virtual heritage is from the first steps to help in restoring the historical building and preserving it. It also helps in documenting the historical building and publishing it online to widen the base of the scientific research in order tomake it available for researchers and interested ones in this field all over the world.

- Through the case study, we find that the virtual reality environment could becreated by using low cost tools. In addition, this technique works stably on personal computers. The suggested structuring for the project is designed to be applied on all the different historical buildings.

- To apply this study practically on other buildings, this requires making use of number specialties in architecture and surveying. As well as, the specialists in history, photography, 3D modelling and programmers. It must provideadequate financial budget.

- The technology used could be developed. The tools change based on the development of the technology of information and communication. Except thatthe methodology is similar and the occurring changes will be under the service of the researchers and the user as it provide more flexible information sources. In the other side, it will help the team working with the virtual heritagetechniques since the technological development will increase the speed of theapplication of these projects and reduce its competence.

- Finally, the research paper presented the example of citadel of Qaitbay in how to use documentation and recording of the architectural heritage using the modern techniques, at the same time to show the documentation and recording for the public and learners. Through documentation and recording, the concept of finding "a laboratory for the urban environment" that allows theconstancy of the heritage environment. This could be done by a responsible organization to collect, register and display all the urban heritage aspects and apply this in many environment.

\section{Recommendations:}

1. The documentation should emerge from a solid belief that these monuments are the balance of the survival of the Egyptian people andevidences that related him with his previous civilization.

2. Working on using the techniques of the virtual heritage through an integrated project that includes the historical buildings in Alexandria as asupporting step in the preservation processes and linked it with the databases of the international organizations specialized in 
this field.

3. The necessity of using the modern techniques in the electronic documentation in the architectural preservation to get the most accurateresults in the registration.

4. The necessity of increasing the awareness of the public and officials withthe importance of preserving the architectural heritage.

5. The necessity of providing the financial support by the Government agencies and other Donor organizations to develop the documentationprocess with its different kinds.

6. Finding the owners of experiences and qualifications to work in the fieldsof preservation and documentation by sending missions or attracting theexpertise.

7. Widening the search base and analyzing using the techniques of thevirtual heritage on the vanished buildings.

\section{Reference}

1- UNESCO- ICCROM, 2003 "Introducing young people to heritage site management and protection" first published, UNESCO Amman office- Jordan.

2- Alian, Beauty (2005), "to maintain the heritage Althagava- toward Arab school to preserve the cultural heritage and its management" - a series ofbooks the world of knowledge, politics Press, Kuwait.

3- Baz, Munir (2006), "Dealing with the elements of the internal architecture of the reemployment of value-building projects" - Master, Faculty of Engineering, Cairo University, Cairo, Arab Republic of Egypt.

4- Balawi, Mahmoud (2010), "a lecture entitled maintaining Urbanism" - Department of Architecture Faculty of Engineering, Islamic University Bgzh-Palestine.

5- Shull, c., (1999) "Photogrammetry and the Archeology of Buildings",unpublished M.Sc. thesis, University of Cape Town, South Africa.

6- Boujemaa, behind God and others (2009) "The role of electronic documentation in the maintenance of urban and architectural heritage inPalestine" - University of M'sila, Algeria.

7- Mohammad, Amal Abdul Waris et al. (2005) "architectural documentation of historic buildings in the light of the digital revolution" - the Sixth InternationalScientific Conference and its impact on architecture and urbanism, Faculty of Engineering, University of Assiut, Egypt.

8- Muheisen, Ahmed et al. (2008), "Study of Center for Architectural Heritagein documenting archaeological and historical sites in Gaza City" - the First International Conference on Architectural Conservation, Center for Architectural Heritage, the Islamic University Bgzh- 
Palestine.

9- Popular Architecture Center "gallery" (2011), "National Register ofmonumental buildings" - Ramallah, West Bank, Palestine.

10- Jaafar, Ashraf (2005), "use" modeling through images "in the three- dimensional positions of the heritage of Islamic architecture in Jerusalem embodiment" methods - paper, scientific research periodical Alengah- refereed issued by the Faculty of Engineering, University of Zagazig BranchBhbra- Pinha- fourth Issue.

11- Jaafar, Ashraf (2004), "The use of virtual reality in the Archaeological Datethreedimensional interactive Pharaonic tombs techniques" - paper, scientific research journal Alengah- refereed journal published by the Faculty of Engineering, University of Zagazig.

12- Mohammed Hefny MOGHAZY, Nagwa Sayed ABDEL RAHIM, Hamdy Abdel Moniem MOHAMMED, Rasha Taha ABBAS, AN APPLIED STUDY FOR THE RESTORATION OF A GLASS LANTERN DAMAGED BY THE EXPLOSION AT THE MUSEUM OF ISLAMIC ART IN CAIRO, International Journal of Advanced Studies in World Archaeology, Vol. 1, No. 1, 2018, pp. 7-9.

Received: July 15, 2018

Accepted: August 20, 2018 